\title{
The Early Modern Origins of Pragmatism
}

\author{
Piotr K. Szalek \\ The John Paul II Catholic University of Lublin
}

BIBLID [0873-626X (2020) 59; pp.433-56]

\begin{abstract}
This paper considers the alleged pragmatism of Berkeley's philosophy using the two Sellarsian categories of 'manifest' and 'scientific' images of the world and human beings. The 'manifest' image is regarded as a refinement of the ordinary way of conceiving things, and the scientific image is seen as a theoretical picture of the world provided by science. The paper argues that the so-called Berkeleian pragmatism was an effect of Berkeley's work towards a synthesis of 'manifest' and 'scientific' images through the creation of one unified synoptic vision of the world and was a part of a new conceptual framework within which these two images could be combined.
\end{abstract}

\section{Keywords}

Berkeley, James, Peirce, pragmatism, representationalism.

One of the most striking readings of Berkeley's philosophy is offered by the two founders of classical American Pragmatism. Both Charles Sanders Peirce and William James regarded Berkeley as a pragmatist. In this paper I identify why Peirce and James perceived Berkeley as a pragmatist, and eventually offer possible explanations as to why Berkeley's philosophy contained some pragmatic elements.

In explaining why there are some pragmatic elements in Berkeley's philosophy, I apply the two famous Sellarsian categories of the 'manifest' and the 'scientific' images of the world and human beings. My initial research hypothesis is that these general interpretative categories, adapted to early modern philosophy, seem to offer the most instrumental tool for understanding the early modern thought's specific character and its relation to the scientific revolution. As this paper argues, the aforementioned categories can help to explain the 
emergence of new problems and conceptual frameworks regarding the early modern period and the intersection of science and philosophy. The 'manifest' image is regarded as a refinement of the ordinary way of conceiving things, and the scientific image is seen as a theoretical picture of the world provided by science (see Sellars 1962: 14-25). I argue that so-called Berkeleian pragmatism was an effect of Berkeley's attempt to synthesize 'manifest' and 'scientific' images by creating one synoptic vision of the world and was a part of a new conceptual framework within which these two images could be combined. As far as the two images are not in a conflict, there is no problem with a synoptic philosophical vision. The manifest image and the scientific, astronomic image of the world are seemingly not in conflict with ancient and medieval times: these images share the same general picture of the world. However, after the modern scientific revolution, the apparent conflict between manifest and scientific images appeared in full force. Copernican astronomy, the microscope, and telescope technologies showed that the scientific image of the world is different from the ordinary or manifest image of the world. The apparent sceptical challenge was whether we are able to reach a true picture of the world if we have these two conflicting images of the world. The task for emerging modern philosophy was a reconciliation of these two visions through offering a new conceptual tool or framework which could deal with these apparently conflicting images.

The argument of this paper will consist of the following three steps. The first step reviews the opinions of Peirce and James which identify Berkeley as a pragmatist (section one). Then in the second step, in order to understand why there are some pragmatic elements in Berkeley's philosophy, this paper introduces the Sellarsian categories needed for elaborating the proposed interpretation of seeing Berkeley's pragmatism as a part of his overall methodological synoptic strategy in the context of the relation of the early modern scientific revolution and philosophy (section two). Finally, the third step examines how Berkeley addressed the sceptical consequences of the early modern scientific revolution in order to offer a synoptic vision which reconciles these conflicting world-views: the scientific and the manifest (section three). In this final section, the paper argues that this synoptic vision took the form of Berkeleian pragmatic 
anti-representationalism. Pragmatism is understood here as a philosophical position or method that emphasises practice as a tool for solving otherwise unsolvable theoretical puzzles connected to representationalism. Representationalism could be explained in terms of the representational theory of perception, thus describing the world as given to us in the form of different representations or theories. A common element of various versions of pragmatism is an attempt to show that we are not able to confirm the truthfulness or adequacy of a given representation or choose between different theories as we do not have access to both sides of comparison: representations and what is represented, and theories and what they describe in the world. The only viable solution is to refer to appropriate practice through the observable and predicable consequences of our perceptual or scientific actions. In such a view of pragmatism, this position is strongly associated with anti-representationalism.

\section{Peirce and James on Berkeley}

Let us start first by reviewing Peirce's and James's interpretations of Berkeley. In his review of the 1871 Fraser edition of the works of George Berkeley, Peirce expresses an opinion that Berkeley should be regarded as the founder of the method of modern pragmatism (see Peirce 1871: 9-38). In his letter to James from 1903, Peirce writes: "Berkeley on the whole has more right to be considered the introducer of pragmatism into philosophy than any other one man [...]" (cf. Perry 1935: 425). In subsequent years Peirce occasionally remarks on Berkeley in the following way. In 1905 he writes: "Pragmaticism is [...] a method of thinking [...] Of those who have used this way of thinking Berkeley is the clearest example [...]" (Peirce 1958: 206, cf. Friedman 2003: 81), and in 1908 he confesses that: "In a metaphysical Club, I used to preach this principle as a sort of logical gospel, representing the unformulated method followed by Berkeley, and in conversation about it I called it 'Pragmatism'” (Peirce 1935b: 482, cf. Friedman 2003: 81). Among many philosophers, it is Berkeley who gains the special status of being the founder of pragmatism as according to Peirce.

Also in the unpublished manuscripts of Peirce we can find some notes on Berkeleian pragmatism. In a 1906 manuscript Peirce states 
that in "An Essay Towards a New Theory of Vision and Principles of Human Knowledge it was pragmatism, not tar-water, that gave health and strength to [these] earlier works" (Peirce 1935a: 11, cf. Friedman 2003: 86). Additionally, in a 1909 manuscript Peirce notes that "every competent critic will recognize in me a disciple of Berkeley", because - as he confesses a little bit further on-Peirce's pragmatic "way of defining concepts was largely derived from Berkeley" (cf. Friedman 2003: 86). ${ }^{1}$ Here Peirce invokes Berkeley as a forerunner of his own concept of the pragmatic method. This is especially significant considering that Peirce was looking at a wide range of historical backgrounds to pragmatism, but only Berkeley received special attention and status.

It is interesting to note that James, like Peirce, saw Berkeley as employing the pragmatic method. In his 1907 Pragmatism: A New Name for Some Old Ways of Thinking, James refers to Berkeley several times. First of all, James turns his attention to Berkeley's way of arguing against material substance. In James' reading, Berkeley does not deny that there is an external world, but pragmatically challenges the idea that there is something lying behind all the attributes experience can reveal. As rightly noted by Robert Schwartz, James's reading of Berkeley's argument is "that no discernible difference in the consequences flow from countenancing such mysterious, inaccessible stuff. Positing material substance does not advance understanding or offer additional explanatory or predicative power" (Schwartz 2012: 75). James writes:

Material substance was criticised by Berkeley with such telling effect that his name has reverberated through all subsequent philosophy. Berkeley's treatment of the notion of matter is so well known as to need hardly more than a mention. So far from denying the external world which we know, Berkeley corroborated it. It was the scholastic notion of a material substance unapproachable by us, behind the external world, deeper and more real than it, and needed to support it, which Berkeley maintained to be the most effective of all reducers of the external world to unreality. Abolish that substance, he said, believe that God, whom you can understand and approach, sends you the sensible world directly, and you confirm the latter and back it up by

\footnotetext{
${ }^{1}$ See also Friedman 1887: 253-4.
} 
his divine authority. Berkeley's criticism of 'matter' was consequently absolutely pragmatistic. Matter is known as our sensations of colour, figure, hardness and the like. They are the cash-value of the term. The difference matter makes to us by truly being is that we then get such sensations; by not being, is that we lack them. These sensations then are its sole meaning. Berkeley doesn't deny matter, then; he simply tells us what it consists of. It is a true name for just so much in the way of sensations. (James 1907: 109-10)

James also interestingly observes in a later section of the book that:

When Berkeley had explained what people meant by matter, people thought that he denied matter's existence. When Messrs. Schiller and Dewey now explain what people mean by truth, they are accused of denying its existence. These pragmatists destroy all objective standards, critics say, and put foolishness and wisdom on one level. A favourite formula for describing Mr. Schiller's doctrines and mine is that we are persons who think that by saying whatever you find it pleasant to say and calling it truth you fulfil every pragmatistic requirement. (1907: 253)

From the above quotations it is clear why James thought that Berkeley was using the pragmatic method as James offers a justification for his opinion. For James, Berkeley was simply showing that there is no meaning associated with the word 'matter' that cannot be explained in other ways with reference to our experience. Our ordinary linguistic practice shows that when we utter a word 'matter' we are referring to sensations of our experience. Berkeley simply redefines the word through reference to the pragmatic consequences of its usage which we can detect empirically.

However, it is hard to find any explanation made by Peirce as to why he thought of Berkeley as a pragmatist. In trying to reconstruct the Peircean understanding of Berkeley's pragmatism, within the reminder of this section I follow some general points of observation made by Lesley Friedman in this regard, adapting them for the specific purposes of this paper. What was likely appealing to Peirce in Berkeley's philosophy was the latter's "rallies" against the "abuse of language", "the deception of words", and the verbal "weeds" that hinder the growth of scientific knowledge (Berkeley 1710: $§ 6,22-3$ ). ${ }^{2}$

${ }^{2}$ All references to Berkeley's works are found in the classical edition pub- 
This is unsurprising as it is well known that Peirce was attempting to rid philosophy of "meaningless surplusage" (Peirce 1935b: 525). As is rightly observed by Lesley Friedman in Peirce's reading of Berkeley, "[i]t is this linguistic 'dust' that has, in no small part, led us to metaphysical absurdities, confusion, and scepticism" (Friedman 2003: 86). In other words, Berkeley's argument against the material substance is an argument against what he takes to be meaningless language. To speak of an unthinking or unperceived thing is to "amuse ourselves with words" (Berkeley 1710: $\S \S 28$ and 88). Moreover, Berkeley opposes "what is certain" or "grounded in experience" with what is only a verbal amusement (see Berkeley 1710: § 28). "'Substance' and like terms have no meaning, for we have experienced neither the corresponding positive idea nor its effects, nor could we ever have had such an experience. Meaningful statements are thus statements of experience, both actual or possible". (Friedman 2003: 88)

The most striking pragmatic element of Berkeley's attitude is seen in the way in which he describes the meaning of the phrase: "the earth is in motion." Both in the Principles and in the Three Dialogues, Berkeley explains the meaning of this phrase as what one would perceive were one observing under certain conditions; "in terms of a subjunctive conditional whose antecedent and consequent are experiential statements" (Friedman 2003: 89). Berkeley writes:

We may, from the experience we have had... be enabled to pass a right judgment of what would have appeared to us, in case we were placed in circumstances very different from those we are in at present. Herein consists the knowledge of nature... [scientific knowledge, not philosophic knowledge]. (Berkeley 1710: §59).

And:

[...] the question, whether the earth moves or no, amounts in reality to no more than this, to wit, whether we have reason to conclude from what has been observed by astronomers, that if we were placed in such and such circumstances, and such or such a position and distance, both from the

lished by Luce and Jessop (1948-57) as well as (where appropriate) in the newest edition by Desmond M. Clarke as published within the series of Cambridge Texts in the History of Philosophy (2008). Besides Principles (quoted by sections), all other quotations are by page numbers. 
earth and sun, we should perceive the former to move among the choir of the planets, and appearing in all respects like one of them. (Berkeley 1710: $§ 58$, emphasis added $)^{3}$

The Berkeleian statements seem to anticipate the pragmatic maxim expressed by Peirce when he claims that to attribute some characteristic to an object is to make a claim about what would be possible, "how it might lead us to act, not merely under such circumstances as are likely to arise, but under such as might possibly occur, no matter how improbable they may be" (Peirce 1935b: 401). The hypothetical conditions of a specific circumstance of observation on a basis of prediction, and confirmed by expected practice, verify the truthfulness of our theory. There is no other way for a theory's verification as we cannot have an external point of view which confronts both theories and reality.

In the New Theory of Vision Berkeley explains that "experience leads us to understand one idea as a sign for another, to become in the habit of associating the two so as to act as if they were forever connected. In the case of distance, what we see is not like the object at all, the relation is neither one of resemblance nor likeness; we are merely in the habit of taking one to signify another because we have observed them together often enough in the past (P[rinciples], [sections] 44-7)" (Friedman 2003: 90-1). These ideas are then connected together by only a habit that is a regularly repeated practice of its own sort. This practice is then a proper instrument to run science and to verify scientific theories. Summing up this stage of our considerations, we can say after Friedman that Berkeley's pragmatic way of defining concepts consists in his assumption that "[m]eaning is unpacked in terms of an instruction for action, or as an expression of our habitually connected ideas" (Friedman 2003: 91). Both interpretations of Schwartz and Friedman, as well as the other pragmatic readings of Berkeley, ${ }^{4}$

\footnotetext{
${ }^{3}$ See also Berkeley 1744: 150-1 and Berkeley 1732: 306.

${ }^{4}$ Such as the interpretations of James A. Moore (1984: 325-42), and, more recently, Richard Van Iten (2015: 83-97). For Moore, pragmatism in Berkeley is only an instrument of Berkeley's linguistic (semiotic) reform, while for Van Iten, Berkeley's pragmatism is a tool for the flourishing of humankind. Both interpretations are right in their respects, but they neglect the more important element that both linguistic and moral aspects are only instantiations of a more gen-
} 
rightly emphasize his instrumentalism as a key pragmatic element of his pragmatism. However, my interpretation seeks to substantiate this by showing that the alleged pragmatism of Berkeley has a more fundamental methodological motivation for its author. Berkeley tried to build a synoptic method of doing philosophy in the face of the failure of representationalism, and his antirepresentational pragmatism was an outcome of this process. Instrumentalism was only one of the instantiations of this general methodological strategy.

\section{Manifest and scientific images of the world}

In the remainder of this paper I seek to explain why we in fact find any pragmatic elements in Berkeley's philosophy as a part of his general methodological approach, not only as a kind of instrumentalism. My research hypothesis is that we can explain this phenomenon in terms of the Sellarsian categories of manifest and scientific images of the world (see Sellars 1962: 14-25; see also Roberts 2007: 125, and Bordner 2011: 333-4). In this reading Berkeley was trying to offer a synoptic vision which could combine these previously mentioned two conflicting images. One can ask why we should use these interpretative categories to look at Berkeley's philosophy. In my view, Berkeley himself gives us an answer to this question. Namely, at the very end of the Three Dialogues, Philonous (porte-parole for Berkeley) declares:

I do not pretend to be a setter-up of 'new notions'. My endeavours tend only to unite, and place in a clearer light, that truth which was before shared between the vulgar and the philosophers: the former be-

eral methodology of Berkeley cashing out anti-representationalism in pragmatic terms. As I argue in the paper, the latter methodology was a part of Berkeley's endeavour to build a synoptic philosophical vision that could reconcile scientific and manifest world views. Only from this background it is possible to understand why Peirce could charitably claim that the first true pragmatist thinker was Berkeley. Additionally, the pragmatic and anti-representational interpretation of Berkeley can make various elements of his thought plausible, with these elements being difficult to combine coherently if they are separated from each other and understood non-pragmatically. However, closer examination of non-pragmatic interpretations of Berkeley extends beyond the limits of this paper and requires a separate study. 
ing of opinion, that 'those things they immediately perceive are the real things'; and the latter, that 'the things immediately perceived, are ideas which exist only in the mind'. Which two notions, put together, do in effect constitute the substance of what I advance. (Berkeley 1734: $242)^{5}$

In order to achieve the declared aim of reconciliation, Berkeley needed to demonstrate that both views have the same empirical consequences. This reconciliation is then the pragmatic spirit of the Berkeleian endeavour. However, this reconciliation is only a part of the explanation, as I will attempt to demonstrate. In my view, the conflict between, on the one hand, the vulgar or manifest image and the philosophers' or the scientific image of the world, and, on the other hand, Berkeley's attempt to offer a synoptic vision is an important theme of the Three Dialogues. Against this background we can understand Berkeley's alleged pragmatism.

Let us recall first the Sellarsian categories. For Wilfred Sellars the aim of philosophy is to understand "how things in the broadest possible sense of the term hang together in the broadest possible sense of the term" (Sellars 1962: 1). Philosophy has its eyes on the whole trying to offer a 'synoptic vision'. However, this synoptic vision becomes hard to achieve in the case when we have conflicting perspectives of man in the world - a manifest image and a scientific image. The manifest image is the conceptual framework in terms of which "man came to be aware of himself as man-in-the-world" (Sellars 1962: 6). The manifest image is that by which man seeks to determine the apparent correlations of the world which man observes in the world (but not in terms of scientific thinking about the world) (see Sellars 1962: 7-8). The task of 'perennial' or classical philosophy was to articulate the contours of this manifest image (see Sellars 1962: 14-8). The scientific image, by contrast, is not concerned with establishing manifest correlations, but with explaining these correlations in terms of the theoretical postulates posited by science (see Sellars 1962: 19-23).

Let us turn now to adapt these categories to the case of Berkeley's philosophy. As far as the two images are not in a conflict, there is no problem for a philosophical synoptic vision. In my opinion, we can

${ }^{5}$ See also Berkeley 1713: 262 
say that such a situation took place in the case of Ptolemaic astronomy by the beginning of the early modern period. ${ }^{6}$ Roughly speaking, the manifest image and the scientific, astronomic image of the world were not in conflict in ancient and medieval times: they shared the same general picture of the world. However, after the modern scientific revolution the apparent conflict between the manifest and scientific images appeared in full force. There are two particular spheres in which this was the most evident: the astronomical picture of the world offered by Copernicus, and the discovery of new technologies such as the telescope and microscope that showed that the picture of things seen by a naked eye could be completely different from the one seen by these instruments (see Yolton 1984: 10-2, 18-22, 124-32, Wilson 1995: 74-8, 176-8, 251-6, and Garber 2001: 66, 77-82, 298-301). The task for modern philosophy was to reconcile these two visions by offering a new conceptual tool or framework to deal with the aforementioned conflicting images.

One of the most striking and crucial conceptual tools introduced by Descartes to gain a synoptic vision was the category of the idea as a representation of a thing (see Descartes 1641: 126-7, and Simmons 2016: 645-52). The new Copernican form of astronomy and the new technologies of the telescope and microscope showed that the scientific image of the world is different from the ordinary or manifest image of the world. The sun is not moving around the earth, but - according to the Copernican view - the earth is moving around the sun, while in the manifest image we see that the sun is moving up and down around the earth during sunrises and sunsets. The world of ordinary objects was conflicting in its image with the world of the objects seen by microscopes or telescopes. The apparent sceptical

${ }^{6}$ The Ptolemaic picture of the world was formulated on the basis of observations of the naked eye and as such was an extrapolation of the ordinary world view, so there was no apparent conflict between the two previously mentioned images. The situation changed radically with the Copernican picture of the world, which stimulated the development of new technology in the form of the telescope for astronomical observations used to verify the Copernican theory. For the first time, humankind got a real extension of their senses, and the apparent collision between the picture of the naked eye and the picture of the optical instrument became a fact. I develop considerations on this topic in a separate paper coming soon (see Evans 1998: 384-92, Crowe 1990: 42-9, and Walker 1996: 187-230). 
challenge was whether we are able to reach a true picture of the world if we have these two conflicting images of the world. The Cartesian idea of a representation of a thing seemed to be an ideal solution. It is then possible to see the same thing through different representations. An idea of a thing in a manifest image referred to the same thing as an idea of the thing in a scientific image. These two conflicting images simply become different representations of the same thing in question.

This solution was very appealing, but caused a serious difficulty for successors of Descartes. The puzzle was: what kind of entity is an idea? Is it something material or mental? How can we be sure about the degree of resemblance of the thing represented by an idea? Does the idea resemble anything behind itself if it is merely the idea that we have direct cognitive access to? There were different solutions to this puzzle. In short, we can say that the solutions were more speculative (like Malebranche's solution; see Malebranche 1674-1678: 482-4, 569-74) and more empirical or minimalist (like Locke's solution; see Locke 1689-1690: 134-5). The most appealing to many was the latter solution. Locke was trying to show that we have in our experience (given through ideas) some elements of the experiences which are objective for sure (i.e. come from the represented things). In order to prove the objective elements of our experience, Locke distinguished between the so-called primary and secondary qualities. The primary qualites, like extension or shape, were something which was essential to a thing, and which was experienced though many senses. While secondary qualities were something dependent upon the subjective conditions of a perceiver and were experienced only through one sense. ${ }^{7}$

\section{Berkeley's synoptic vision of the world}

Berkeley's Three Dialogues offers a very apt criticism of the Cartesian

${ }^{7}$ The discussion over the nature of ideas as representations constitutes a major point of controversy for the early modern period and was covered by an immense amount of secondary literature. There is no space to consider this in more detail as this paper focuses on Berkeley's pragmatism. However, I extend the above considerations on the nature of ideas in the forthcoming paper. 
and Lockean solutions, showing how they failed to give a synoptic vision. This failure of the philosophical synoptic visions was a major concern for Berkeley as it was leading in a direct route to scepticism: due to having conflicting images of the world and the failure of their reconciliation, we cannot determine which of the images offers a true picture of the world.

In order to face this sceptical challenge, Berkeley needed to offer a new synoptic vision. However, this vision had to avoid all the weak points of the visions offered by Descartes and Locke. In consequence, the First Dialogue consists in a series of criticisms of these previous visions, while the Second and Third Dialogues offer a way in which to reconcile manifest and scientific images. In the first two editions of the Dialogues, Berkeley writes in the sub-title that the aim of the book is "to open a method for rendering the sciences more easy, useful, and compendious." This sub-title was omitted from the third 1734 edition. However, in this edition he added a preface in which he includes the three following significant declarations which are worth quoting in extenso. In the first declaration, Berkeley says:

Though it seems the general opinion of the world, no less than the design of nature and providence, that the end of speculation be practice, or the improvement and regulation of our lives and actions; yet those who are most addicted to speculative studies seem as generally of another mind. (Berkeley 1734: 151) ${ }^{8}$

Practice is then a solution when a theoretical answer is not satisfactory for representational puzzles.

The second declaration of Berkeley states as follows:

In this treatise, which does not presuppose in the reader any knowledge of what was contained in the former, it has been my aim to introduce the notions I advance, into the mind, in the most easy and familiar manner; especially because they carry with them a great opposition to the prejudices of philosophers, which have so far prevailed against the common sense and natural notions of mankind. (Berkeley 1734: 152) ${ }^{9}$

Here Berkeley explicitly seeks to reconcile the scientific and manifest picture of the world, emphasising that his philosophy is presented in

\footnotetext{
${ }^{8}$ See also Berkeley 1713: 167.

${ }^{9}$ See also Berkeley 1713: 168.
} 
a way familiar to ordinary people, but yet being in conformity with current science.

In the third declaration Berkeley claims that that:

If the principles, which I here endeavour to propagate, are admitted for true; the consequences which, I think, evidently flow from thence are that atheism and scepticism will be utterly destroyed, many intricate points made plain, great difficulties solved, several useless parts of science retrenched, speculation referred to practice, and men reduced from paradoxes to common sense. (Berkeley 1734: 152) ${ }^{10}$

Berkeley therefore emphasises practice as a criterion for the verification of his proposal (a pragmatic element), and conformity of the manifest image to the scientific one in his philosophical exposition (a synoptic element). These two elements are shown as strictly correlated to each other in Berkeley's view. Let's turn now to see how these declarations are realized in the Dialogues.

In the First Dialogue, Berkeley addresses two mentioned solutions: Cartesian representationalism and the Lockean theory of the distinction between primary and secondary qualities. In this dialogue, Berkeley also refers frequently to the science of vision echoing his own considerations from the New Theory of Vision. Berkeley recalls the scientific image of the world in order to demonstrate that the scientific image does not imply the existence of substantial matter. He writes: "[The principles and theorems of sciences] are universal intellectual notions, and consequently independent of matter; the denial therefore of this does not imply the denying them" (Berkeley 1734: 156). ${ }^{11}$

In several passages of the First Dialogue, Berkeley is demonstrating the apparent conflict between the scientific and manifest images of objects of the world. He writes:

But a microscope often discovers colours in an object different from those perceived by the unassisted sight. And in case we had microscopes magnifying to an assigned degree, it is certain that no object whatsoever, viewed through them, would appear in the same colour which it exhibits to the naked eye (Berkeley 1734: 167-8 and

\footnotetext{
${ }^{10}$ See also Berkeley 1713: 168.

${ }^{11}$ See also Berkeley 1713: 173.
} 
Berkeley 1713: 184).

Berkeley detects here a conflict between different pictures of the same thing seen by a microscope and by a naked eye. Analysing this case further he adds:

Consequently the microscopical representation is to be thought that which best sets forth the real nature of the thing, or what it is in itself. The colours, therefore, by it perceived are more genuine and real than those perceived otherwise (Berkeley 1734: 168) ${ }^{12}$

Here he emphasises the primacy of the scientific picture as something more refined and probably more accurate. However, in a further passage, Berkeley demonstrates a perspectival aspect of seeing things even by a naked eye:

Even our own eyes do not always represent objects to us after the same manner. In the jaundice, everyone knows that all things seem yellow. Is it not therefore highly probable, those animals in whose eyes we discern a very different texture from that of ours and whose bodies abound with different humours, do not see the same colours in every object that we do? From all which should it not seem to follow, that all colours are equally apparent, and that none of those which we perceive are really inherent in any outward object? (Berkeley 1734: 168) ${ }^{13}$

The case shows that everything depends on our perspective, and every representation is equally subjective. In other words, representationalism is not a good solution for conflicting images of the world. Berkeley subsequently introduces a competing solution:

Nay, all other circumstances remaining the same, change but the situation of some objects and they shall present different colours to the eye. The same thing happens upon viewing an object in various degrees of light. And what is more known, than that the same bodies appear differently coloured by candle-light from what they do in the open day? Add to these the experiment of a prism, which separating the heterogeneous rays of light, alters the colour of any object; and will cause the whitest to appear of a deep blue or red to the naked eye. And now tell me, whether you are still of opinion that every body has its true real colour inhering in it; and if you think it has, I would fain know farther

\footnotetext{
${ }^{12}$ See also Berkeley 1713: 185 .

${ }^{13}$ See also Berkeley 1713: 185.
} 
from you, what certain distance and position of the object, what peculiar texture and formation of the eye, what degree or kind of light is necessary for ascertaining that true colour and distinguishing it from apparent ones (Berkeley 1734: 169) ${ }^{14}$

Thus perspective, physiological conditions, and all circumstances in general should be taken into consideration, and by a practical verification attached as a proper description to the world. This is even emphasised in the following passage:

Is it not the very same reasoning to conclude, there is no extension or figure in an object because to one eye it shall seem little, smooth, and round, when at the same time it appears to the other, great, uneven, and angular? [...] You may at any time make the experiment, by looking with one eye bare, and with the other through a microscope. (Berkeley 1734: 172) $)^{15}$

The practically and experimentally verifable conditions of an experiment make it be seen in some way or another. The main line of Berkeley's argument here lies in showing that we have two conflicting images of things, and that we are not able to say which of them offers the correct picture of the world. Even if we assume that we have different representations of the same object in these images, we are not able to demonstrate which of the representations offers a true representation of the object in question, as we have direct cognitive access merely to an object's representation, not to the object in question. In this situation a synoptic vision based on the theory of ideas as representations of things fails. Philonous asks rhetorically in that context: "how can any determinate material objects be properly represented or painted forth by several distinct things, each of which is so different from and unlike the rest? Or if you say it resembles some one only of our ideas, how shall we be able to distinguish the true copy from all the false ones?" (Berkeley 1734: 188; see also Berkeley 1713: 206).

Berkeley was aware that in trying to find a solution to this puzzle of representational theory we can try to evoke the theory of primary and secondary qualities. Hylas, the opponent of Philonous, is trying

\footnotetext{
${ }^{14}$ See also Berkeley 1713: 186.

${ }^{15}$ See also Berkeley 1713: 189.
} 
to prove that even if we do not have a reliable idea of the represented thing, we still have an access to the thing through an experience of its qualities. And in this experience we can distinguish between experiential qualities which come from a perceiving subject and the ones which come from a perceived object. However, Berkeley heavily criticises this distinction by showing that both sorts of qualities are actually purely subjective. Interestingly, he discusses these issues by echoing his own considerations from the New Theory of Vision with reference to visual experience from a distance and the Molyneux problem. Berkeley writes:

You are still then of opinion that extension and figures are inherent in external unthinking substances [...] But what if the same arguments which are brought against secondary qualities, will hold good against these too? (Berkeley 1734: 171)

Berkeley suggests here that primary qualities, like secondary ones, are equally subjective, i.e. they do not belong to objects. He supports his claim with the following argument:

But as we approach to or recede from an object, the visible extension varies, being at one distance ten or a hundred times greater than at another. Does it not therefore follow from hence likewise, that it is not really inherent in the object? (Berkeley 1734: 172) ${ }^{17}$

And he adds:

Sight therefore does not suggest, or any way inform you, that the visible object you immediately perceive exists at a distance, or will be perceived when you advance farther onward, there being a continued series of visible objects succeeding each other, during the whole time of your approach (Berkeley 1734: 184) ${ }^{18}$

Berkeley emphasises that even the most paradigmatic primary quality, such as visible extension, changes depending on the distance or location of the perceiver. Therefore, even primary qualities depend on the perceiver's conditions or circumstances and are as equally subjective as the secondary, purely subjective qualities are supposed

\footnotetext{
${ }^{16}$ See also Berkeley 1713: 188.

${ }^{17}$ See also Berkeley 1713: 189.

${ }^{18}$ See also Berkeley 1713: 201.
} 
to be. This line of the argument leads Berkeley to the following conclusion:

Now is it not plain, that if we suppose a man born blind was on a sudden made to see, he could at first have no experience of what may be suggested by sight. (Berkeley 1734: 184) ${ }^{19}$

Thus referring to the Molyneux problem and following his own observations after cataract removal surgery, Berkeley argues that there is no automatic transition (transmodality) between senses or sensual objective properties. In other words, a blind person after gaining sight is not able to recognize by a sight such primary qualities like shape as known previously only by touch. In fact, every quality is equally subjective: there is an apparent difference between shape as given by touch and shape as given by sight. There is no property or true nature of things inherited from the things themselves. Berkeley analyses figure, extension, motion, and solidity to demonstrate that they are equally subjective as the so-called secondary qualities such as colour or sound. Philonous concludes that:

Consequently the very same arguments which you admitted as conclusive against the secondary qualities are, without any farther application of force, against the primary too. (Berkeley 1734: 177) ${ }^{20}$

The representational theory of ideas and the attempt to save the objectivity of experience by introducing the primary qualities failed as a synoptic vision that tried to combine the two conflicting images of the world: scientific and manifest. If we are not able to say what the true picture of the world is, we are led to scepticism. Philonous concludes his reasoning in the First Dialogue in the following way: "So I have gained my point, which was to show your principles led to scepticism” (Berkeley 1734: 189, see also Berkeley 1713: 206).

The anti-representationalism endorsed by Berkeley in the First Dialogue leads to a pragmatic criterion for the verification of the existence and nature of things. This enterprise was elaborated by Berkeley in the Second and Third Dialogues. The pragmatic criterion was a tool for his synoptic vision of the world, in which he proposed

\footnotetext{
${ }^{19}$ See also Berkeley 1713: 202.

${ }^{20}$ See also Berkeley 1713: 194.
} 
the esse est percipi thesis (with all supplementary epistemological and metaphysical claims). If we cannot escape from the sceptical consequences of the Cartesian and Lockean failure of a reconciliation of the two conflicting images of the world (manifest and scientific), what is left is a reference to the practice of life. Berkeley writes: "But surely, Hylas, I can distinguish gold, for example, from iron; and how could this be, if I knew not what either truly was?" (Berkeley 1734: 208$)^{21}$

He adds a little bit further:

I assure you, Hylas, I do not pretend to frame any hypothesis at all. I am of a vulgar cast, simple enough to believe my senses, and leave things as I find them. To be plain, it is my opinion that the real things are those very things I see and feel, and perceive by my senses. These I know, and finding they answer all the necessities and purposes of life, have no reason to be solicitous about any other unknown beings. A piece of sensible bread, for instance, would stay my stomach better than ten thousand times as much of that insensible, unintelligible, real bread you speak of. (Berkeley 1734: 210)22

This passage seems to suggest that by reference to the practice of life, Berkeley wants to reconcile the scientific and ordinary world views. He substantiates this by saying:

But I, who understand by those words the things I see and feel, am obliged to think like other folks. And as I am no sceptic with regard to the nature of things, so neither am I as to their existence. (Berkeley 1734: 211$)^{23}$

And, following this line of the argument, subsequently adds:

Wood, stones, fire, water, flesh, iron, and the like things, which I name and discourse of, are things that I know; [otherwise I should never have thought of them or named them.] (Berkeley 1734: 211)24

The above statement serves as a basis for Berkeley's famous claim that

\footnotetext{
${ }^{21}$ See also Berkeley 1713: 228.

${ }^{22}$ See also Berkeley 1713: 229.

${ }^{23}$ See also Berkeley 1713: 230.

${ }^{24}$ See also Berkeley 1713: 230.
} 
"to be is to be perceived." Perceptual practice then becomes a tool for refuting representational scepticism:

Their existence therefore consists in being perceived; when therefore they are actually perceived, there can be no doubt of their existence. Away then with all that scepticism, all those ridiculous philosophical doubts. (Berkeley 1734: 211) ${ }^{25}$

Experience as a criterion of confirmation of the real existence of the world is possible only through our normal, ordinary perceptual practices that can help us to act and orientate successfully in the world. The pragmatic criterion consists in assuming that we have true knowledge about things if we can act upon them successfully. If our actions achieve what they aimed to, we know things correctly. Pragmatic consequences of our actions are revealed in experience, so experience is a proper framework for implementing this pragmatic criterion when assessing the validity of our knowledge of the existence and nature of things. A synoptic vision which could combine manifest and scientific images should rely then on experience as an instrument for the pragmatic verification of our knowledge about the world.

However, experience is always expressed in a language in which we categorize the world. Berkeley writes:

Let us suppose several men together, all endued with the same faculties, and consequently affected in like sort by their senses, and who had yet never known the use of language; they would without question agree in their perceptions. Though perhaps, when they came to the use of speech, some regarding the uniformness of what was perceived, might call it the 'same' thing; others especially regarding the diversity of persons who perceived, might choose the denomination of different things. But who sees not that all the dispute is about a word: to wit, whether what is perceived by different persons may yet have the term 'same' applied to it? (Berkeley 1734: 228) ${ }^{26}$

Equipped with the same faculties and language as a part of our human nature, we can detect through the common practice of life that the most essential dispute about the material character of the world

\footnotetext{
${ }^{25}$ See also Berkeley 1713: 230.

${ }^{26}$ See also Berkeley 1713: 247-8.
} 
is simply verbal:

With all my heart: retain the word 'matter' and apply it to the objects of sense, if you please, provided you do not attribute to them any subsistence distinct from their being perceived. I shall never quarrel with you for an expression. (Berkeley 1734: 241) ${ }^{27}$

In these terms Berkeley is trying to show that if we really rely on our experience, the differences in the descriptions of the world are merely verbal ones. In consequence, Berkeley proposed a pragmatic verification of the meaning of language by the means of experience. The thesis esse est percipi could be regarded as an instantiation of this pragmatic strategy for defining the most basic concepts or categories of the Berkeleian synoptic vision.

\section{Conclusions}

To conclude, Berkeley indeed endorses pragmatic anti-representationalism, which might be seen as an early form of the pragmatism promoted both by Peirce and James. It is plausible to say then that Berkeleian philosophy could be described as the early modern antecedent of their subsequent pragmatism. As argued in this paper, in understanding why there are pragmatic elements in Berkeley's philosophy, the two famous Sellarsian categories of the 'manifest' and the 'scientific' images of the world are instrumental. The 'manifest' image is explained here as a refinement of the ordinary way of conceiving things, and the scientific image is characterised as a theoretical picture of the world provided by science. According to this paper's interpretation, Berkeley's pragmatism was an effect of his attempt to synthesize the 'manifest' and 'scientific' images by creating one unified synoptic vision of the world and was a part of a new conceptual framework within which these two images could be combined. As far as the two images are not in a conflict, there is no problem for the synoptic vision. The manifest and scientific images of the world were apparently not in conflict in ancient and medieval times. After the early modern scientific revolution, however, a conflict between these two images emerged, and in consequence, led 
to a sceptical challenge for early modern philosophy. New trends in philosophy had to establish what the true picture of the world is when one is presented with two conflicting images of the world. In that context, the task for Berkeley was to find a way to reconcile these two conflicting images by offering a new conceptual tool or framework to combat the sceptical outcome of the collision of these two images. It effectively motivated Berkeley towards a pragmatic strategy: a successful synoptic vision which could combine manifest and scientific images and relied on experience as an instrument for the pragmatic verification of our knowledge concerning the world. In that way, Berkeley could be thought of as "the founder of the method of modern pragmatism" as Peirce wanted to see him (see Peirce 1871: 9-38). ${ }^{28}$

Piotr K. Szalek Faculty of Philosophy John Paul II Catholic University of Lublin Al. Raclawickie 14 20-950 Lublin, Poland piotr.szalek@kul.pl

\section{References}

Berkeley, George. 1709. An Essay Toward a New Theory of Vision. In The Works of George Berkeley, Bishop of Cloyne, ed. by A. A. Luce and T. E. Jessop, vol. 1.

${ }^{28}$ The work on this paper was possible due to a generous support of the $\mathrm{Na}$ tional Science Centre, Poland (NCN Sonata 14 grant no. 2018/31/D/HS1/03759, 2019-2022) and at the initial stage of the research by the Fulbright Committee, which granted me the Senior Fulbright Award at the Department of Philosophy, Harvard University (2016-2017), and for which I am enormously grateful to both institutions. I would like to express my special gratitude for many insightful comments on this paper to Alison Simmons and Simon Blackburn. The earlier drafts of this paper were presented at the Harvard History of Philosophy Workshop (14 $4^{\text {th }}$ of May 2017) and the 2019 Joint Session of the Aristotelian Society and Mind Association at Durham University $\left(19^{\text {th }}-21^{\text {st }}\right.$ July 2019). The Durham presentation was supported by a conference grant from the Minister of Science and Higher Education, Poland, within the program under the name 'Regional Initiative of Excellence' in 2019-2022 (project number: 028/RID/2018/19). I would like to thank both audiences at Harvard and Durham for a stimulating and helpful discussion, especially to Jeffrey K. McDonough and Paul Croce. 
London-Edinburgh: Nelson, 1948.

Berkeley, George. 1710. A Treatise concerning the Principles of Human Knowledge. In The Works of George Berkeley, Bishop of Cloyne, ed. by A. A. Luce and T. E. Jessop, vol. 2. London-Edinburgh: Nelson, 1949.

Berkeley, George. 1710. A Treatise concerning the Principles of Human Knowledge. In George Berkeley, Philosophical Writings (Cambridge Texts in the History of Philosophy Series), ed. by D.M. Clarke. Cambridge: Cambridge University Press, 2008.

Berkeley, George. 1713. Three Dialogues between Hylas and Philonous. In The Works of George Berkeley, Bishop of Cloyne, ed. by A. A. Luce and T. E. Jessop, vol. 2. London-Edinburgh: Nelson, 1949.

Berkeley, George. 1734. Three Dialogues between Hylas and Philonous. In George Berkeley, Philosophical Writings (Cambridge Texts in the History of Philosophy Series), ed. by D.M. Clarke. Cambridge: Cambridge University Press, 2008.

Berkeley, George. 1732. Alciphron; or The Minute Philosopher. In The Works of George Berkeley, Bishop of Cloyne, ed. by A.A. Luce and T.E. Jessop, vol. 3. London-Edinburgh: Nelson, 1950.

Berkeley, George. 1744. Siris: A Chain of Philosophical Reflexions and Inquiries Concerning the Virtues of Tar-water, and Divers Other Subjects Connected Together and Arising One from Another. In The Works of George Berkeley, Bishop of Cloyne, ed. by A. A. Luce and T. E. Jessop, vol. 5. London-Edinburgh: Nelson, 1953.

Bordner, S. Seth. 2011. Berkeley's "defense" of "commonsense". Journal of the History of Philosophy 49: 315-38.

Crowe, Michael J. 1990. Theories of the World from Antiquity to the Copernican Revolution. Mineola, NY: Dover Publications.

Descartes, René. 1641. The Philosophical Writings of Descartes, ed. and trans. by J. Cottingham, R. Stoothoff, and D. Murdoch, vol. 1. Cambridge: Cambridge University Press, 1984.

Evans, James. 1998. The History and Practice of Ancient Astronomy. New York: Oxford University Press.

Friedman, Lesley. 1997. Peirce's reality and Berkeley's blunders. Journal of the History of Philosophy 35: 253-68.

Friedman, Lesley.2003. Pragmatism: the unformulated method of Bishop Berkeley. Journal of the History of Philosophy 41: 81-96.

Garber, Daniel. 2001. Descartes Embodied: Reading Cartesian Philosophy through Cartesian Science. Cambridge: Cambridge University Press.

James, William. 1907. Pragmatism. A New Name for Some Old Ways of Thinking. New York: Longmans, Green and Co.

Locke, John. 1689-1690. An Essay Concerning Human Understanding, ed. by P.H. Nidditch. Oxford: Clarendon Press, 1975.

Malebranche, Nicolas. 1674-1678. The Search after Truth and Elucidation of the Search after Truth, ed. and trans. by T.M. Lennon and P.J. Olscamp. 
Columbus: Ohio State University Press, 1980.

Moore, James A. 1984. The semiotic of Bishop Berkeley. A prelude to Peirce? Transactions of the Charles S. Peirce Society 20: 325-42.

Peirce, Charles Sanders. 1871. Fraser's The Works of George Berkeley. In Collected Papers of Charles Sanders Peirce, ed. by A.W. Burks, vol. 8, 9-38. Cambridge, Mass.: Harvard University Press, 1958.

Peirce, Charles Sanders. 1935a. Collected Papers of Charles Sanders Peirce, ed. by Ch. Hartshorne and P. Weiss, vol. 5. Cambridge, Mass.: Harvard University Press.

Peirce, Charles Sanders. 1935b. Collected Papers of Charles Sanders Peirce, ed. by Ch. Hartshorne and P. Weiss, vol. 6. Cambridge, Mass.: Harvard University Press.

Perry, Ralph Barton. 1935. The Thought and Character of William James. Boston: Little and Brown.

Roberts, John Russell. 2007. A Metaphysics for the Mob: The Philosophy of George Berkeley. Oxford-New York: Oxford University Press.

Schwartz, Robert. 2012. Rethinking Pragmatism. From William James to Contemporary Philosophy. Oxford: Wiley-Blackwell.

Sellars, Wilfred. 1962. Philosophy and the Scientific Image of Man. In Wilfred Sellars. Science, Perception, and Reality, 1-40. New York: Humanities Press, 1963.

Simmons, Alison. 2016. Representation. In The Cambridge Descartes Lexicon, ed. by L. Nolan, 645-652. Cambridge: Cambridge University Press.

Van Iten, Richard. 2015. Berkeley's pragmatic bent. In Berkeley Revisited: Moral, Social and Political Philosophy, ed. by S. Charles, 83-97. Liverpool: Liverpool University Press.

Walker, Christopher (ed.). 1996. Astronomy Before the Telescope. London: British Museum Press.

Wilson, Catherine. 1995. The Invisible World. Early Modern Philosophy and the Invention of the Microscope. Princeton: Princeton University Press, 1997.

Yolton, John W. 1984. Perceptual Acquaintance from Descartes to Reid. Minneapolis: University of Minnesota Press. 